\title{
HOW THE SUBPRIME CRISIS WENT GLOBAL: EVIDENCE FROM BANK CREDIT DEFAULT SWAP SPREADS
}

\author{
Barry Eichengreen \\ Ashoka Mody \\ Milan Nedeljkovic \\ Lucio Sarno \\ Working Paper 14904 \\ http://www.nber.org/papers/w14904 \\ NATIONAL BUREAU OF ECONOMIC RESEARCH \\ 1050 Massachusetts Avenue \\ Cambridge, MA 02138 \\ April 2009
}

The authors are respectively with the University of California, Berkeley; the International Monetary Fund; the University of Warwick; and the Cass Business School and the Centre for Economic Policy Research. They are grateful to Charlie Kramer for comments and to Susan Becker and Anastasia Guscina for valuable research assistance. The views expressed here are those of the authors and should not be attributed to the International Monetary Fund, its management, its Executive Directors, or the National Bureau of Economic Research.

NBER working papers are circulated for discussion and comment purposes. They have not been peerreviewed or been subject to the review by the NBER Board of Directors that accompanies official NBER publications.

(C) 2009 by Barry Eichengreen, Ashoka Mody, Milan Nedeljkovic, and Lucio Sarno. All rights reserved. Short sections of text, not to exceed two paragraphs, may be quoted without explicit permission provided that full credit, including (C) notice, is given to the source. 
How the Subprime Crisis Went Global: Evidence from Bank Credit Default Swap Spreads Barry Eichengreen, Ashoka Mody, Milan Nedeljkovic, and Lucio Sarno

NBER Working Paper No. 14904

April 2009

JEL No. F36,G15,G18

\begin{abstract}
How did the Subprime Crisis, a problem in a small corner of U.S. financial markets, affect the entire global banking system? To shed light on this question we use principal components analysis to identify common factors in the movement of banks' credit default swap spreads. We find that fortunes of international banks rise and fall together even in normal times along with short-term global economic prospects. But the importance of common factors rose steadily to exceptional levels from the outbreak of the Subprime Crisis to past the rescue of Bear Stearns, reflecting a diffuse sense that funding and credit risk was increasing. Following the failure of Lehman Brothers, the interdependencies briefly increased to a new high, before they fell back to the pre-Lehman elevated levels - but now they more clearly reflected heightened funding and counterparty risk. After Lehman's failure, the prospect of global recession became imminent, auguring the further deterioration of banks' loan portfolios. At this point the entire global financial system had become infected.
\end{abstract}

Barry Eichengreen

Department of Economics

University of California, Berkeley

549 Evans Hall 3880

Berkeley, CA 94720-3880

and NBER

eichengr@econ.Berkeley.edu

Ashoka Mody

Research Department

International Monetary Fund

700 19th Street, NW

Washington, DC 20431

amody@imf.org

\author{
Milan Nedeljkovic \\ Department of Economics \\ The University of Warwick \\ Gibbet Hill Road \\ Coventry, CV4 7AL, UK \\ milan.nedeljkovic@warwick.ac.uk \\ Lucio Sarno \\ Cass Business School \\ 106 Bunhill Row \\ London, EC1Y 8TZ, UK \\ United Kingdom \\ lucio.sarno@city.ac.uk
}




\section{INTRODUCTION}

One enduring question about the financial turbulence that engulfed the world starting in the summer of 2007 is how problems in a small corner of U.S. financial marketssecurities backed by subprime mortgages accounting for only some 3 per cent of U.S. financial assets - could infect the entire U.S. and global banking systems. This paper seeks to shed further light on that question. We analyze the risk premium on debt owed by individual banks as measured by banks' credit default swap (CDS) spreads, focusing on the CDS spreads of the 45 largest financial institutions in the United States, the United Kingdom, Germany, Switzerland, France, Italy, Netherlands, Spain and Portugal. ${ }^{2}$

We use principal components analysis to extract the common factors underlying weekly variations in the CDS spreads of individual banks. If the spreads for different banks move independently, then we can infer that the risk of bank failure is driven by bank-specific factors. If they move together then we infer that banks are perceived as subject to common risks. This provides us with the first bit of evidence on how the crisis spread.

In addition to estimating the importance of common factors we attempt to ascertain what they reflect. We examine the correlation between the common factors on the one hand and real-economy influences outside the financial system, transactional relationships among

\footnotetext{
${ }^{2}$ These swaps are insurance contracts. The buyer of the CDS makes payments to the seller in order to receive a payment if a credit instrument (e.g. a bond or a loan) goes into default or in the event of a specified credit event, such as bankruptcy. The spreads are, in effect, a measure of the credit risk or the insurance premium charged. Although CDS spreads are implicitly spreads on the issuers' bonds, they have the advantage, as Longstaff et al. (2008) point out, that they are "less encumbered by covenants and guarantees." However, there has been a recent concern that speculative pressure within the CDS market sometimes causes the swaps to become delinked from their function of hedging against default (Soros, 2009). Longstaff et al. (2008) analyze spreads on sovereign CDS, whereas Zhang, Zhou, and Zhu (2008) examine the determinants of spreads on corporate CDS spreads.
} 
banks, and transactional influences between banks and other parts of the financial system on the other. ${ }^{3}$

We reach three conclusions. First, the share of common factors was already quite high, at 62 percent, prior to the outbreak of the Subprime Crisis in July 2007. Banks' fortunes rose and fell together to a considerable extent, in other words, even before the crisis. These common factors were correlated with U.S. high-yield spreads - the premium paid relative to Treasury bonds by U.S. corporations that had less than investment grade credit ratings - which we take as an indicator of the perceived probability of default by less creditworthy U.S. corporations, which in turn reflects economic growth prospects. ${ }^{4}$ For obvious reasons, those defaults and the growth performance that drives them have major implications for the condition of the banking system even in normal times.

The share of the variance accounted for by common factors then rose to 77 percent in the period between the July 2007 eruption of the Subprime Crisis and Lehman's failure in September 2008. This is indicative of a perception that banks as a class faced higher common risks than before. At the same time, the correlation between the common factors and U.S. high-yield spreads declined, while the correlation with measures of banks' own credit risk and of generalized risk aversion increased (Brunnermeier, 2009). An interpretation is that the Subprime Crisis made investors more wary about the risks in bank

\footnotetext{
${ }^{3}$ To be clear, we do not attempt to identify causality. However, the correlations offer a rich set of stylized characterizations. These characterizations are likely to be the basis for defining and probing more subtle hypotheses.

${ }^{4}$ These high-yield spreads have been found to be good predictors of U.S. growth at horizons of about a year, reflecting a financial-accelerator interaction between credit markets and the real economy (Mody and Taylor, 2003). Because European high-yield spreads are closely correlated with US spreads and, as such, offer no additional information, U.S. high-yield spreads (spreads of corporations with less than investment-grade rating) are also a measure of global prospects.
} 
portfolios for reasons largely independent of the evolution of the real economy but that lack of detailed information on those risks led them to treat all banks as riskier rather than discriminating among them.

Following Lehman's failure, there was a further brief increase in the share of the variance accounted for by the common components. Then, although the level of CDS spreads remained high, the share of their variation accounted for by the common component fell back relatively quickly to levels about those that prevailed just before the Lehman episode. In other words, the common movements declined from their peaks but remained at the postBear Stearns elevated levels. Thus, the perception persisted that the banks' fortunes were linked. The correlation between the common factors and high-yield corporate spreads also reemerged, evidently reflecting the perception that a global recession was now in train. More importantly, the common component of CDS spreads became more highly correlated with measures of funding and credit risk as measured by spreads in the asset-backed commercial paper market and LIBOR minus the overnight index swap. An interpretation is that whereas in the July 2007-September 2008 period investors became more aware of systemic risk in an unfocused sense, Lehman's failure caused that common risk to be more concretely identified with both developments in the real economy and specific problems in the financial system.

In sum, then, our answer to the question posed in the title is thus as follows. Banks fortunes rise and fall together even in normal times. But the importance of common factors rose to exceptional levels between the outbreak of the Subprime Crisis and the rescue of Bear Stearns, reflecting increased diffuse sense that credit risk was increasing. The period following the failure of Lehman Brothers then saw a further increase in those interdependencies, reflecting heightened funding and counterparty risk. In addition there 
were direct spillovers, as opposed to common movements, from the CDS spreads of U.S. banks to those of European banks. After Lehman's failure the prospect of global recession became imminent, auguring the further deterioration of banks' loan portfolios. At this point the entire global financial system had become infected.

It is helpful to be clear about what this paper does not do. It does not pinpoint any one bank or set of banks as systemically-important. Rather, the extent of comovement in spreads points to tendencies of the degree to which the system is perceived to be tied to common factors. An individual bank within the set examined may be more or less tied to the common factors to the extent that it has a large or small extent of idiosyncratic risk. Ultimately, then, the methodology outlined here is a guide for policy only to the extent that it highlights overall trends. The task of determining the systemic importance of an individual bank requires examining the data in the books of the banks - or worse, at data that should be on the books but is not.

The rest of the paper is organized as follows. Section II specifies a dynamic factor model in which common latent factors explain the movement of the CDS spreads of the 45 banks in our sample. The model is estimated using principal components analysis, allowing the contributions of the components to change over time. In Section III, we consider the possibility of additional spillovers from inter-bank exposures that go beyond the common movements identified by the latent factors. Then in Section IV, we describe the changing correlations between these latent factors and a number of high frequency financial series. A final section concludes. 


\section{COMMON FACTORS IN CDS SPREADS}

We start by decomposing the movement in credit default swap (CDS) spreads of 45 global banks into common and idiosyncratic components. ${ }^{5}$ The sample runs from July 29 , 2002 to November $28,2008 .^{6}$ The data are 5-year CDS spreads, the five year maturity being the most widely traded. We use end-of-day quotes from the New York market for payment in U.S. dollars based on U.S. dollar-denominated notional amounts. As is customary, the spreads are denominated in basis points (100 basis points equal 1 percentage point). These are averaged over the week to obtain a weekly series, smoothing out sharp daily movements and irregular trading, yielding 331 observations per bank. The data are from Bloomberg.

\section{II.1 Preliminary data analysis}

Table 1 reports summary statistics on spreads for 45 banks. Average spreads over the period vary significantly across banks (from a low of 17 for Rabobank to a high of 101 basis points for AIG). ${ }^{7}$ Our interest is not so much in the cross-sectional variation at this stage, however, as in the variation over time, which has been substantial. Unlike sovereign CDS spreads where the standard deviations are typically smaller than the means, the standard deviations of the CDS spreads of financial institutions studied here are close to the means and sometimes larger. The minimum/maximum values further highlight the considerable

\footnotetext{
${ }^{5}$ The term "banks" is used throughout, although some insurance companies are also included in the sample.

${ }^{6}$ Thereafter, the intense involvement of the U.S. authorities in managing the short-term vulnerability of the financial sector increasingly reflects the official interventions, which, because they operated differentially across the institutions, limits the validity of a market-driven common set of influences on their CDS.

${ }^{7}$ This variation is, however, smaller than the 100-fold variation in premia across the Japanese and Brazilian sovereigns in the sample analyzed by Longstaff et al. (2008).
} 
time-series variation. For example, the spread for Merrill Lynch ranges from 15 to 473 basis points; in Europe, the range for Commerzbank varies from 8 to 260 basis points.

Figure 1 tracks the time variation in median spreads for all banks, U.S. banks, and European banks. In 2002, after the tech bubble burst and confidence was challenged by the events of September 11, 2001, CDS spreads were elevated. Some banks were able to purchase protection at relatively low spreads of 20-50 basis points, but others paid more than 100 basis points. Subsequently spreads declined everywhere. The low point was the week of January 17, 2007 when the median spread in the full sample of 45 banks was 7.5 basis points. Thereafter, spreads increased gradually, reaching a median of 12 basis points in the second week of July 2007. But even in that week, the highest spread was 55 basis points for Bear Stearns. ${ }^{8}$ In contrast, the subsequent rise in spreads was dramatic with twin peaks corresponding to the Bear Stearns rescue and the Lehman Brothers failure. For U.S. banks, a high of 417 basis points was reached following the severe stress after the Lehman failure during the week of October 1, 2008; the median spread then moderated to 268 basis points in the last week of November 2008. The corresponding numbers for the European banks were 130 and 97 basis points, respectively.

\section{II.2 A dynamic factor model of CDS spreads}

The first question we ask is whether the movements in spreads reflected common drivers. To answer that question we estimate the "latent" or unobserved factors generating common movements. The relationship between these unobserved factors $\left(F_{t}\right)$ and the

\footnotetext{
${ }^{8}$ Someone, evidently, new about the extent of its leverage.
} 
observed spreads $\left(X_{i, t}\right)$ can be approximately represented by a dynamic factor model (Chamberlain and Rothchild, 1983):

$$
X_{i, t}=\Lambda_{i} F_{h, t}+\phi_{i}(L) X_{i, t-1}+\varepsilon_{i t}
$$

$X_{i, t}$ is a vector of the weekly changes in CDS spreads of each of the 45 banks, where " $i$ " refers to a bank and " $t$ " is the time subscript. $\Lambda_{i}$ is a matrix of factor loadings, and $F_{h, t}$ are latent factors $(\mathrm{h}=1, \ldots, \mathrm{k})$. The estimation procedure allows for $X_{i, t}$ to be serially correlated and for $\varepsilon_{i t}$ to be cross-sectionally correlated and heteroscedastic. ${ }^{9}$ Stacking the terms, specification (1) can be equally represented as:

$$
X=F \Lambda^{\prime}+\Phi(L) X+\varepsilon
$$

where $X$ and $\varepsilon$ are TxN matrices, $F$ is a Txk, and $\Lambda$ is a Nxk matrix.

The idea here is that the covariance among the series can be captured by a few unobserved common factors. The latent factors and their loadings can be consistently estimated by the method of principal components. As Bai and $\mathrm{Ng}(2002,2008)$ and Stock and Watson (2002) show, the principal component (PC) estimator enables us to identify factors up to a change of sign and consistently estimate them up to an orthonormal transformation. ${ }^{10}$ The procedure also provides a measure of the fraction of the total variation explained by each factor, which is computed as the ratio between the k largest eigenvalues of the matrix $X^{\prime} X$ divided by the sum of all eigenvalues.

\footnotetext{
${ }^{9}$ Note, however, that the contribution of the idiosyncratic covariances to the total variance needs to be bounded (Bai and $\mathrm{Ng}, 2008$ ), which puts a limit on the amount of cross-correlation and heteroscedasticity.

${ }^{10}$ Note that the consistency is related to the space spanned by the factors and not with respect to the individual factor estimates. Under standard regulatory conditions, Bai and $\mathrm{Ng}$ (2008) establish consistency of the estimates of the factor space provided that $\mathrm{T} / \mathrm{N}^{2} \rightarrow 0$, which holds in our case.
} 
The data for each bank are first filtered for autocorrelation since in the presence of serial correlation the covariance matrix of the data will not have the factor structure (exact or approximate) and as such can lead to biased inference. To assess the changes over time, the model is estimated recursively after the first 150 data points: as such, the filtering is also performed recursively. At each recursion an $\operatorname{AR}(p)$ model is applied to each series, where the order, $p$, is determined using the individual partial autocorrelation function (PACF) and residuals from the $\operatorname{AR}(p)$ model are used as the filtered series. The data is then tested for nonstationarity and, as expected, unit root tests indicate no evidence of nonstationarity in the series. ${ }^{11}$ Finally, all series are standardized at each recursion since principal component estimates are not scale invariant.

\section{II.3 Estimation results and discussion}

Figure 2 shows changes over time in the contributions of the common factors to the total variance in the CDS data. Recall that up until mid-July 2007, i.e., before the start of the subprime crisis, absolute movements in bank CDS spreads were small. The principal components analysis shows that even in this relatively tranquil period the perceived riskiness of different international banks moved together to a considerable extent. The first component contributed just above 40 percent of these movements and the second a further 10 percent. Together the first four common factors explained about 60 percent of movements in CDS spreads in this period. ${ }^{12}$ The statistical procedure does not tell us of course whether these

\footnotetext{
${ }^{11}$ To save space, these results are not reported.

${ }^{12}$ Factors other than the first four individually explained less than 4 percent of the variation. Thus, our analysis below focuses on the PC estimates obtained using the four factor "space." This is supported by the results obtained by running the Onatski's (2006) criterion for determination of the number of factors in the data
} 
common influences reflected interconnections within the banking system or were the result of common external factors. To explore that distinction, in Section IV, we report evidence on the correlations of the common "unobserved" factors and observed variables representing real economic prospects and metrics of banks' funding stress and their systemic credit risk. A new phase commenced in July 2007, when HSBC announced large subprime-mortgage related losses and CDS spreads rose sharply. While spreads retreated somewhat in the months thereafter, they remained at significantly higher levels. Nevertheless, July 2007 saw the start of a tendency towards an increase in the comovement of spreads. The rise in the share of variance explained by the first factor and the first four factors combined trended up even as the average spreads rose and fell. Thus, while the sense of crisis went into remission periodically in late 2007 and early 2008, the perception remained that banks faced common risks. By early March 2008, prior to the rescue of Bear Stearns, the share of the first component had risen by about 15 percentage points to 56 percent.

The importance of the common factors continued to increase following the Bear Stearns rescue, reaching a new high in May 2008, at which point the first common factor explained almost 60 percent of the variance of CDS spreads. Then, the period between May and September 2008 was one of general weakness of financial-market indicators. The share of the variance explained by common components of CDS spreads exhibited some slight tendency to decline in this period, although it remained not very far below the high level reached in May.

\footnotetext{
through a grid of parameter values. The Bai and $\mathrm{Ng}$ (2002) information criterion does lead to the possibility of more than four factors, but this criterion tends to overestimate the number of factors in samples with relatively small cross-sections and high cross-correlations (Anderson and Vahid, 2007, Onatski, 2006). As a practical matter, our results remain the same with either 3 or 5 factors.
} 
The failure of Lehman Brothers was accompanied by a further increase in comovement of spreads. ${ }^{13}$ The share of the variation accounted for by the first principal component jumped to 65 percent, while the share accounted for by the first four reached 80 percent. However, there was moderation of the comovement by the first week of October, as the share of the variance accounted for by the common factors fell back to pre-Lehman levels.

To get a sense of whether the degree of commonality we observe for international banks is high or low, we can compare these results with those of Longstaff et al. (2008) for sovereign CDS spreads. Longstaff et al. found that the fraction of the variance of spreads on the CDS of 26 sovereigns explained by the first component varied between 32 and 48 percent. Note that they used monthly (rather than weekly) changes in spreads and the higher share is for months in which observations were available for all sovereigns. These features of their analysis smooth out some part of the idiosyncratic movements and, to that extent, might overstate the commonality. As such, the initial - pre-subprime — contribution of the first component of banks' spreads at about a 40 percent share is at least in a comparable range, and possibly implies greater commonality. That share of the first component for the banks, as we have reported, then rose to approximately 60 percent just before the Lehman failure and further to 65 percent just after. When considering the first four components, Longstaff et al. (2008) find that they explain 60 to 70 percent of the share of sovereign spreads variation, which is comparable to our range of 60 to 80 percent. The implication also is that for sovereign spreads, the second component and beyond have a more substantial contribution

\footnotetext{
${ }^{13}$ As well as in the aggregate share of all four components.
} 
than is the case for banks, implying greater variety of global common influences on sovereign spreads.

\section{AdDitional SpILLOVERS}

In this section, we investigate whether, once the common factors are considered, the CDS spread of a particular bank is further influenced by current and lagged changes in CDS spreads of other banks. In other words, we ask whether there is significant information in CDS spreads of other banks over and above that contained in the common factors.

These spillover tests are performed by regressing the change in the (non-filtered) CDS spread of a bank "i" on its own lags, the common factors, and the (lagged and current) changes in CDS spreads of another bank (bank “ $\mathrm{j}$ ), as in equation (3). Since the CDS data exhibit a break in the last week of July 2007 we also added a dummy variable for the sub-prime period, where $D_{t}=X_{j, t-1} I(t \geq \tau):^{14}$

$$
X_{i, t}=\Lambda_{i} F_{h, i}+\phi_{i}(L) X_{i, t-1}+\lambda_{j}(L) X_{j, t-1}+\delta D_{t}+u_{i t}
$$

Equation (3) was estimated for each pair of banks, which yielded a total of 2025 regressions.

In each case, we tested for the statistical significance of the coefficients $\lambda_{j}$ by computing the heteroskedascity robust Lagrange multiplier (LM) test of specification (3). ${ }^{15}$ The restrictions are tested using a standard $\chi^{2}$ test. ${ }^{16}$

\footnotetext{
${ }^{14}$ Bai and Ng (2006a) showed that the so-called "factor-augmented" regressions yield consistent estimates of the parameters as $T, N \rightarrow \infty$ provided that $\sqrt{ } \mathrm{T} / \mathrm{N} \rightarrow 0$. Of course, in a finite sample the estimation error will not disappear completely.

${ }^{15}$ The heteroscedasticity robust estimate of the covariance matrix was obtained using the Davidson and MacKinnon (1985)'s transformation of the squared residuals.

${ }^{16}$ Simulation results in Clark and McCracken (2005) and Rossi (2005) establish that the likelihood ratio test (and other asymptotically equivalent tests) does not lose power to detect the significance of variables in OLS
} 
In only about $2 \frac{1}{2}$ percent of the 2025 possible relationships is the CDS spread of another bank significant at the 5 percent significance level. This supports the validity of the common factors estimated in the preceding section. ${ }^{17}$ The relatively few additional spillovers we identify are illustrated in Figure 3(a). Following the start of the sub-prime crisis, the incidence of such spillovers declined, implying that the commonality is well captured by the latent factors. However, the additional spillovers increased notably starting in mid-July 2008 and reached their maximum during the Lehman Brothers crisis. An interpretation is that not just global economic drivers (which are presumably being picked up by the common factors) but also counterparty risk and other similarities in a few banks' portfolios (which are being captured by the additional spillovers) figured importantly in individual CDS spreads around the time of the Lehman Brothers failure. ${ }^{18}$ The banks for which additional spillovers matter tend to be well-known names: they include ING, Rabobank, Royal Bank of Scotland, and UBS in Europe, and Bank of America, J.P. Morgan, and Morgan Stanley in the United States.

Our procedure also allows us to glean some evidence of international spillovers. Here we consider the percentage of banks in the U.S. significantly influenced by a bank in the

regression subject to the structural break provided that the relationship existed for any subsample (i.e. before or after the break). It is well known that in the presence of breaks and heteroscedasticity, all classical tests may be oversized (Hansen, 2000). We also run the robust bootstrap LM test based on the fixed design wild bootstrap (Hansen, 2000) and recursive wild bootstrap (Goncalves and Kilian, 2004), but the results were not significantly different. In addition, we also performed a battery of Monte Carlo experiments using the robust LM and Wald statistics (with and without bootstrapping) and while both tests had similar power properties the LM test had more conservative rejection rates.

\footnotetext{
${ }^{17}$ In contrast, if we estimate the same specification without controlling for common factors, more than half of the relationships show (misleading) evidence of spillovers. In other words, the presence of common factors that drive spreads reflecting common vulnerabilities faced by banks better characterizes the co-movements of bank spreads than direct influences from one bank to another.

${ }^{18}$ The importance of counterparty problems due to the failure of Lehman Brothers is emphasized by, inter alia, Jones (2009).
} 
European Union (Figure 3b) and vice versa (Figure 3c). Note that we are not looking here at pairwise influences; rather the question is what percentage of banks has at least one crossborder relationship with evidence of additional spillovers. ${ }^{19}$

The period before the sub-prime crisis is relatively stable with moderate evidence of spillovers from the European Union to the U.S. (Figure 3b) and little evidence of spillovers from the U.S. banks to European banks (Figure 3c). Following the start of the crisis in July 2007, in contrast, the incidence of additional spillovers from the U.S. system to Europe increased, particularly in periods of high distress (in August 2007 and from the beginning of July 2008 onwards). Interestingly, the magnitude of additional spillovers from European to U.S. banks declined in this period. This is consistent with a view that developments in U.S. banks were the stronger source of perceived financial risk starting in the early stages of the subprime crisis.

\section{Correlating LATENT Factors With ObSERVEd FinanCial VARIABLES}

The next step is to look for economic correlates of the latent factors identified in Section II. We first present findings that correlate the "space" spanned by the first four principal components. We then discuss correlations separately for the first and the second principal components. ${ }^{20}$

\footnotetext{
${ }^{19}$ Clearly, this leads to a larger fraction of banks than where the assessment is on a pairwise basis.

${ }^{20}$ An alternative approach would be to regress observed CDS spreads on a combination of bank-specific and macro variables. Such an approach would, in principle, allow the bank-specific variables to account for the idiosyncratic movements and the macro variables to explain the common movements. Since our immediate interest is in the common changes, a statistically-rigorous examination of correlations between the latent CDS factors - identified in the first stage of our analysis - with observed macro variables appears the most direct approach. The regression approach may also be misleading in this context since, even when the observed series are highly correlated with the factors, they might still be found to be weakly correlated with the CDS data if the variance of the idiosyncratic component is large.
} 


\section{IV.1 Some Statistical Considerations}

There are several approaches to studying such correlations. Bai and $\mathrm{Ng}$ (2006b) have developed statistical criteria to investigate whether any candidate observed series yields the same information that is contained in the set of factors. The general idea is to examine if the observed series can be represented as a linear combination of the latent factors allowing for a limited degree of noise in the relationship. Instead of examining the relationship with the entire factor space, the observed series can also be correlated with a particular factor subspace, including a particular factor. Ahn and Perez (2008) implement an estimation procedure that consistently determines the number of factors that can be related to the set of observable series of interest. ${ }^{21}$ Once this number of factors is determined, the individual correlations between factors and the observed series can be examined. The Ahn and Perez analysis makes the strong assumption of independence between the idiosyncratic part of the movement in CDS spreads and the observed series. If that assumption is invalid, then the results will be biased since the rejections of the null hypothesis of no correlation may occur for any number of factors related to the observables. To obtain robust results we therefore adopt a pre-step estimation procedure to validate the series of observables we use. ${ }^{22}$

\footnotetext{
${ }^{21}$ This procedure is essentially an extension of Andrews and Lu's (2001) general approach to model and moment selection in the generalized method of moment (GMM) estimation.

${ }^{22}$ Given the structure of the procedure and if the true number of factors is known and equal to $\mathrm{k}$, then for $\mathrm{m}$ observed series it follows that if we reject the null hypothesis that $\mathrm{m}(\mathrm{N}-\mathrm{k})$ moment conditions are zero, this may happen only if the instruments (observed series) are correlated with a subset of the idiosyncratic errors. If the observed series were correlated with all idiosyncratic errors, then this would imply the existence of another factor in the data. The pre-step procedure can be seen as leading to a conservative selection of correlates since we exclude all observable series that are correlated with both the factors and idiosyncratic variations: the selected observables are then very robust. The useful pre-step therefore is to compute a J-test using standard optimal HAC weighting matrix for $\mathrm{m}(\mathrm{N}-\mathrm{k})$ moment conditions and test whether the null can be rejected. Following the non-rejection of the null, Ahn and Perez (2008)'s model selection procedure can be applied; otherwise the set of observed series needs to be reconsidered.
} 
Further considerations apply to each approach — that relating the observed series to the space of factors and the individual factor correlates. With regard to the Bai and $\mathrm{Ng}$ (2006b) R-squared and NS criteria, it is not straightforward to determine the threshold that would signal a "matching" between the factor space and individual series of interest when the relationship is contaminated with some degree of noise. With regard to correlations with individual factors, the concern is whether these correlations uniquely identify the relationships with a particular factor. For instance, finding a correlation of 0.5 between the first factor and a series of interest may genuinely reflect a correlation but may also be spuriously picking up a correlation between the second factor and the series. This is a direct consequence of the non-consistency of the individual PC estimates, irrespective of whether the unobserved factors are correlated or not. In general, the literature has not fully dealt with these issues. It is commonplace to report the criteria and the correlations without acknowledging their non-uniqueness. To evaluate the seriousness of these limitations, we used a Monte Carlo experiment to investigate how these procedures behave to reassure ourselves that the results are meaningful and robust. ${ }^{23}$

\footnotetext{
${ }^{23}$ We perform two sets of experiments (not reported but available upon request). Both experiments are designed as to resemble the characteristics of the (change in) CDS data. We allow for the data to be crosscorrelated and heteroskedastic and subject to a break in volatility and occasional outliers. In the first experiment the factors explain a roughly equal percentage of total variation, whereas the second experiment captures the situations when the first factor explains the largest part of the overall variance and when its importance increases after the break point. The "observable" series are generated through a linear relationship with factor(s) with a varying degree of noise. The R-squared and NS criterion and simple correlations between observable series and the estimates of the first two factors were obtained using 5000 simulations. Ahn and Perez's (2008) GMM-based BIC criteria were computed using 1000 simulations and 100 randomizations to save on computing time. The main findings from the experiment are the following. First, the GMM-based BIC criterion performs fairly well selecting in all cases the correct number of factors. The proposed pre-step estimation captures whenever the series are correlated with the idiosyncratic errors. Second, the R-squared and NS estimates are significantly lower (higher) than those proposed by Bai and $\mathrm{Ng}(2006 \mathrm{~b})$ when there is some noise in the relation and breaks in volatility. In particular, the R-squared estimates we highlight below are meaningful measures of the relationships of interest under the moderate levels of noise. Third, the signal-to-noise ratio from using correlations as a proxy improves with the difference in the importance of factors. The second experiment shows
} 


\section{IV.2 Correlates}

We limit our attention to U.S. variables, since the corresponding European variables are highly correlated with U.S. series. A first set of variables representing the real economy includes the corporate default risk measured by the high-yield spread (HYS), risk aversion (VIX), and returns on the S\&P stock index. ${ }^{24} \mathrm{~A}$ second set of variables representing the banks' financial risks includes the credit risk spread (LIBOR minus overnight index swap), liquidity spread (overnight index swap minus the Treasury bill yield), and spreads on asset backed commercial paper $(\mathrm{ABCP}){ }^{25}$

The GMM-based model and moment selection criterion of the validity of the observed series is performed first and the results are presented in Table 2 . The test is performed for the full sample and two sub samples (up to July 2007 and up to May 2008) in order to examine whether the most recent period (with possible outliers) is influencing the results. In the first column of Table 2 we can see that none of the proposed series is correlated with the idiosyncratic part of CDS spreads since the frequency of rejections of the null among all randomizations of the data is very small for all samples. This implies that we can use the moment selection criterion to investigate the relationship between the observed series and the factors. In turn, the results from full and sub-sample estimation of the criterion

\footnotetext{
that finding a high correlation between the first factor and individual observed series cannot be an artifact of correlation between the other factor and that series. The same does not hold when the factors have a similar contribution to the overall variation in the data.

${ }^{24}$ VIX is the implied volatility on the S\&P 100 (OEX) option and is a widely used measure of global risk aversion.

${ }^{25}$ As with the CDS data, all series are recursively filtered and checked for nonstationarity and are standardized prior to the estimation of the correlations.
} 
suggest that the information in the set of observed series is correlated with the three or four factor subspace and that the patterns followed by the individual series are not spurious. ${ }^{26}$

\section{IV.3 The Real Economy Prior to the Subprime Crisis}

In the "real economy" group, we consider three correlates. High-yield spreads (HYS, spreads on bonds issued by less-than-investment-grade issuers) reflect increased corporate default probabilities and do well in predicting short-term growth prospects (Mody and Taylor, 2003). The S\&P 500 average reflects the market's perception of the economic outlook, while the VIX is a measure of economic volatility embedded in stock price movements.

Figure 4 shows the evolution of (median) CDS spreads in relation to these observed variables. Prior to the start of the subprime crisis, the HYS and the VIX trended down along with the median CDS spreads. As the figure suggests and we show below, the real economy as represented by the stock market bore less short-term relationship with the movement in CDS spreads. The HYS, VIX, and CDS spreads were all at low levels prior to July 2007. And while they rose subsequently, their short-term movements became less correlated between the start of the subprime crisis and the failure of Lehman Brothers.

In Figure 5, panel A, we show the correlation of the first four factor space with HYS; this was relatively high prior to the subprime crisis. The R-squared criterion gives a value of 0.5 on the eve of the subprime crisis. In contrast, the correlation with the S\&P returns is

\footnotetext{
${ }^{26}$ For the full sample, the various criteria suggest the existence of a relationship between the series and four factors. For the sub-samples BIC1 suggests a relationship with only one factor, whereas three or four factors are picked by other criterion. Given that apart from the first factor, all other factors may be perceived as weak, BIC1 may underselect the true number of relationships, as shown in the simulation study. On the other hand, BIC3 and HQQ tend to overselect the true number of relationships. As such we base our inference on BIC2.
} 
low-the R-squared is less than 0.1. Notice that the R-squared for the VIX lies in between, but at 0.2 is at the lower end of the range.

The implication is that perceptions of banks' risk in that tranquil period were shaped by a global factor that is best summarized by corporate default risk. This is reasonable not just because of the banks' direct exposure to default risk but also because HYS have a proven track record as a forward-looking predictor of economic prospects (Mody and Taylor, 2003). In particular, HYS movements capture the operation of the financial accelerator: high spreads imply high expected default rates (and hence lower collateral), lower credit supply, reduced growth prospects, and hence higher spreads. HYS has also been found to be a significant explanatory variable of emerging market spread differences across countries and movements over time (see Eichengreen and Mody, 2000, and Longstaff et al., 2008, who find it to be the most potent of their candidate variables). In contrast, stock returns include both upside and downside movements: while high stock returns presumably lower risk to a degree, banks' risks are apparently more clearly defined by downside risks as reflected in the HYS. The fact that the correlation with the VIX is significantly smaller than for HYS suggests that a generalized risk aversion does not necessarily translate into banks' risk premia.

These interpretations are supported by the correlations with specific factors reported in Panel B of Figure 5. Up through the start of the subprime crisis, the HYS was most highly correlated with the first principal component of CDS spreads. ${ }^{27}$ In contrast, there was almost no correlation with the second factor. The same was true the VIX (panel C). In contrast, S\&P returns had a higher correlation with the second factor (panel D). An interpretation is that the first factor reflects global perceptions of downside risks, while the second gives more weight

\footnotetext{
${ }^{27}$ Hereafter, all the correlations are expressed in absolute terms for the ease of comparison.
} 
to general movements in expected future profitability. Note, though, that the second factor explains a much smaller fraction of the overall variance of CDS spreads. Hence returns had a much weaker association with spreads' movements.

\section{IV.4 The Emergence of Financial Factors}

Thus, prior to the subprime crisis, global economic factors as summarized in the HYS were the main drivers of the CDS spreads of international banks. Following the onset of the crisis and through the Bear Stearns bailout, however, the correlation with the HYS declined (Figure 5, panel A). The decline in the overall correspondence between the HYS and the factor space reflected a decline in correlation with the increasingly important first factor of CDS spreads and occurred despite some increase in correlation with the second factor (panel B). Evidently, there was some dissociation with the real economy despite the fact that banks' prospects appear to have been perceived as increasingly correlated with one another in this period. Intuitively, the common risk did not obviously emanate from a sense of worsening of economic prospects. Moreover, an initial sharp increase in correlation with the VIX, reflecting generalized risk aversion, died down to pre-crisis levels by the time of Bear Stearns (Figure 5, panels A and C). The small rise in the correlation between S\&P returns and the CDS factor space probably reflects that that fears about the stability of the banking system were driven more by problems in the banks' positions in securities than by the ability of their corporate customers to stay current on their loans.

Once the subprime crisis started, the relevance of financial variables, particularly those related to banks' credit and funding risks, acquired greater prominence. A common metric of banks' credit risks is the TED spread, or the difference between the interest rates on 
interbank loans (we use the US dollar, 3-month LIBOR) and short-term U.S. government debt (3-month US Treasury bills). This captures the risk premia on bank borrowing, since LIBOR is the rate at which banks borrow and Treasury bills (T-Bills) are considered riskfree.

However, the TED spread reflects not just banking sector credit risk but also includes liquidity or flight-to-quality risk. These two categories of risks can be approximately decomposed. TED=(LIBOR-OIS)+(OIS-“T-Bill”), where the OIS is an "overnight index swap;" which measures the expected daily average Fed Funds rate over the next 3 months. Thus, TED can be decomposed into the banking sector credit risk premium (LIBOR-OIS) and liquidity or flight-to-quality premium (OIS-T-Bill). ${ }^{28}$

The TED spread rose sharply in the post-Lehman-crisis period as Figure 6 shows. While the liquidity premium (the OIS-T-Bill differential) also increased, the more substantial increase was in the credit risk (the LIBOR-OIS differential). Note also the spike after the start of the subprime crisis in the spread on asset-backed commercial paper. Since banks use these instruments for their short-term funding, the rise in this spread proxies the risks associated with rollover in short-term funding. That the market for asset-backed commercial paper issued by banks and conduits collapsed within days of the Lehman bankruptcy is well known; see Jones (2009). ${ }^{29}$

\footnotetext{
${ }^{28}$ Of course, the OIS-TB spread picks up some credit risk, but most analysts now view the "general collateral" repo rate as the "risk free" rate, and that plots very closely to the OIS rate. The LIBOR-OIS spread is analyzed by Taylor (2009) and critiqued by Jones (2009).

${ }^{29}$ Note also from Figure 6 that the LIBOR-OIS spread moved rather closely with the spreads on asset-backed commercial paper, often used to proxy the banks' costs of funding since banks issue such paper to fund their investments.
} 
The correlation of the common factors with these financial variables, which had been historically close to zero, rose following the start of the crisis (Figure 7). Thus perceived bank risk, which had previously stemmed mainly from the development of the real economy, now stemmed more from banks' own internal credit and funding risks. But while liquidity risk (as captured by the OIS-T-bill spread) and the ABCP spread showed some correlation with the CDS factor space initially, those correlations were not sustained. In contrast, the correlation with credit risk was sustained. Credit risk had the largest correlation of these three financial variables with the factor space after the start of the crisis; in particular, the correlation with the first factor rose steadily up until Bear Stearns.

While the change in the pattern of correlations clearly points to greater emphasis on the internal workings of the banking system (rather than to the broader global economy), the correlations we find even at their elevated levels during this phase are small. ${ }^{30}$ To the extent that banks' credit risk and funding risk did become more important, our measures for these features may not be sufficiently encompassing. In addition other concerns, such as lack of transparency of the complex asset holdings, may have also acquired greater prominence in assessing bank risks.

Not much changed between the Bear Stearns rescue and the Lehman failure. The correlation with HYS stabilized at below pre-crisis levels and the correlation with credit risk remained significantly above pre-crisis levels. The other correlations remained low, near their pre-crisis levels. Thus while corporate default risk remained a salient factor determining

\footnotetext{
${ }^{30}$ Thus, to a degree the rise in the share of the first component (and first four components) of CDS spreads remains a matter for further investigation.
} 
banks' risk, there was a shift as this traditionally-dominant factor lost ground and the risk that banks themselves may not be able to honor each others obligations gained prominence.

\section{5 After Lehman}

The immediate post-Lehman phase is remarkable for the unprecedented alignment of risks. The correlation between the CDS factor space and all of their correlates rose, according the R-squared criterion, with the correlations with the financial variables increasing most sharply. The increase in credit and funding risk premia reflected the stress faced by banks. In addition, these developments presumably contributed to a revision of prospects of the real economy that further undermined confidence in the condition of and prospects for the banking system.

By the R-squared criterion, the correlation between the space of common factors in bank CDS spreads and the HYS increased following the failure of Lehman, reversing its decline in the preceding four-plus quarters. The correlation with the $S \& P$ returns showed a particularly large increase as global economic prospects were seen as increasingly tied to the fortunes of banks. In contrast, despite the high level of VIX during this period, the correlation between the CDS factor space and VIX increased relatively little. In contrast, there was an especially sharp increase in the correlation between the financial variables and the common factor in banks' CDS spreads.

Differences in the correlations between these real and financial variables and the first and second common factors provide further intuition. The financial stress indicators became more correlated with the first factor of CDS spreads; that correlation rose to levels that had not been seen before. In contrast, the real economic variables, particularly the HYS, that had 
moved the first factor in the past, declined sharply in importance in the immediate postLehman phase. Instead, the correlation between the real economy and the common CDS movements shifted to the smaller, second factor.

\section{Conclusions}

We have analyzed common factors in bank credit default swaps both before and during the credit crisis that broke out in July 2007 in order to better understand how this crisis spread from the subprime segment of the U.S. financial market to the entire U.S. and global banking system. We showed first common factors in CDS spreads are present even in normal times; they reflect the impact of the macroeconomy — the ultimate common factor from this point of view—on banks as a group. But the importance of the common factor increased significantly between the eruption of the Subprime Crisis in July 2007 and the failure of Lehman Brothers in September 2008. This increase in the common factor seems to have been associated with a proxy for the banking-sector credit-risk premium, especially in the period prior to the rescue of Bear Stearns. In contrast, the correlation with the state of the real economy, which had been evident prior to the crisis, appears to have been somewhat attenuated. In this abnormal period investors, in other words, investors were not yet concerned so much with the prospect of a global recession that would impact the banks' loan books as with other credit risks affecting the banks - connected, presumably, with their investments in subprime related securities.

After the failure of Lehman Brothers the importance of the common factor remained elevated. But where movements in that factor had previously been related to diffuse measures of generalized banking-sector credit risk, they now became increasingly linked to 
measures of funding risk. In addition, the correlation of the common factor with the real economy reasserted itself, as evidence of the deepening recession mounted.

What does this evidence imply for policy decisions taken in this period? With benefit of hindsight (which is what a retrospective statistical analysis permits), we can see a substantial common factor in banks' CDS spreads that could have alerted the authorities to the risks of allowing a major financial institution to fail. The further increase in that common factor in the period between the outbreak of the Subprime Crisis and the critical decision concerning Lehman Brothers should have implied further caution in this regard. It was not the implications of any impending economic slowdown about which investors were primarily worried in this period; rather the concern was about the state of the banks' asset portfolios and, presumably, their investments in securities in particular. The heightened comovement at least in part reflected incomplete knowledge about the magnitude of toxic asset positions in this relatively early stage of the crisis, and, hence, raised the possibility that instability could spread more quickly and widely than assumed in the consensus view. In the event, Lehman Brothers was allowed to fail, after which the sensitivity of the CDS spreads of global banks as a group experienced heightened sensitivity to the whole range of economic and financial variables. As those variables deteriorated, the result was a perfect storm. 
Table 1: The Sample of Financial Institutions

\begin{tabular}{|c|c|c|c|c|c|}
\hline & Mean & $\begin{array}{l}\text { Standard } \\
\text { deviation }\end{array}$ & Median & Minimum & Maximum \\
\hline Abbey & 26.29 & 27.36 & 15.16 & 4.51 & 137.93 \\
\hline Barclays & 28.45 & 37.81 & 12.21 & 5.65 & 251.89 \\
\hline HBOS & 35.64 & 54.12 & 13.78 & 4.84 & 385.86 \\
\hline HSBC & 23.73 & 23.88 & 14.01 & 4.99 & 134.96 \\
\hline Lloyds TSB & 22.39 & 27.24 & 12.30 & 3.87 & 184.40 \\
\hline RBS & 28.84 & 39.71 & 13.02 & 4.00 & 289.11 \\
\hline Standard Chartered & 31.65 & 30.37 & 18.59 & 5.87 & 176.73 \\
\hline Allianz & 36.19 & 27.76 & 24.92 & 6.03 & 136.59 \\
\hline Commerzbank & 45.81 & 41.82 & 27.05 & 8.14 & 221.83 \\
\hline HVB & 43.24 & 36.41 & 29.64 & 6.32 & 167.81 \\
\hline Deutsche Bank & 31.38 & 28.54 & 18.29 & 10.11 & 161.68 \\
\hline $\begin{array}{l}\text { Dresdner Bank } \\
\text { Hannover }\end{array}$ & 34.73 & 30.22 & 22.00 & 5.52 & 154.83 \\
\hline Rueckversicherung & 44.88 & 30.08 & 34.67 & 8.17 & 138.25 \\
\hline Münchner Hypoth. & 32.31 & 20.56 & 25.56 & 5.78 & 120.19 \\
\hline Monte dei Paschi & 30.90 & 24.31 & 21.03 & 6.17 & 137.93 \\
\hline UniCredit & 28.27 & 25.28 & 16.06 & 7.65 & 133.66 \\
\hline AXA & 49.19 & 46.95 & 27.93 & 9.11 & 235.14 \\
\hline BNP Paribas & 20.51 & 19.01 & 12.31 & 5.51 & 103.83 \\
\hline Credit Agricole & 24.19 & 27.47 & 13.27 & 6.08 & 145.56 \\
\hline $\mathrm{LCL}$ & 24.58 & 27.61 & 12.58 & 6.16 & 150.27 \\
\hline Société Générale & 24.85 & 27.11 & 13.25 & 5.97 & 138.93 \\
\hline ABN AMRO & 26.79 & 29.92 & 15.03 & 5.26 & 172.69 \\
\hline ING & 26.54 & 31.12 & 15.44 & 4.45 & 163.93 \\
\hline Rabobank & 16.83 & 22.49 & 8.35 & 3.12 & 131.92 \\
\hline Banco Santader & 31.46 & 30.47 & 16.89 & 7.68 & 143.98 \\
\hline Credit Suisse & 38.98 & 35.44 & 20.87 & 9.04 & 169.57 \\
\hline UBS & 29.04 & 43.34 & 11.63 & 4.55 & 276.23 \\
\hline Banco Comerc. Port. & 33.20 & 28.23 & 21.86 & 8.20 & 145.36 \\
\hline American Express & 59.97 & 90.51 & 25.84 & 9.07 & 603.16 \\
\hline $\mathrm{AIG}$ & 101.24 & 310.18 & 24.87 & 8.57 & 2624.15 \\
\hline Bank of America & 35.03 & 33.93 & 21.34 & 8.47 & 191.45 \\
\hline Bear Sterns & 60.14 & 62.51 & 34.47 & 19.01 & 574.31 \\
\hline Chubb & 39.28 & 29.26 & 29.94 & 10.01 & 153.70 \\
\hline Citibank & 43.19 & 54.79 & 20.83 & 7.52 & 351.93 \\
\hline Fed. Mortgage & 22.81 & 14.09 & 20.67 & 6.35 & 82.55 \\
\hline Freddie Mac & 21.77 & 14.77 & 19.03 & 5.28 & 83.10 \\
\hline Goldman Sachs & 57.72 & 64.67 & 34.33 & 18.95 & 437.37 \\
\hline Hartford & 67.82 & 111.88 & 36.36 & 10.82 & 826.17 \\
\hline JP Morgan & 44.05 & 31.96 & 31.37 & 11.81 & 174.98 \\
\hline Lehman Brothers & 86.00 & 127.03 & 36.74 & 19.49 & 641.91 \\
\hline Merrill Lynch & 68.94 & 77.04 & 34.60 & 15.61 & 417.10 \\
\hline Met Life & 62.58 & 108.22 & 30.46 & 11.20 & 790.42 \\
\hline Morgan Stanley & 73.21 & 117.44 & 34.42 & 18.59 & 1153.09 \\
\hline Safeco & 46.01 & 34.38 & 32.88 & 18.04 & 181.00 \\
\hline Wachovia & 52.70 & 84.18 & 21.42 & 10.40 & 741.79 \\
\hline
\end{tabular}


Table 2: The Validity of the Correlates

\begin{tabular}{|l|l|l|l|l|l|l|}
\hline $\begin{array}{l}\text { The Set of } \\
\text { Correlates }\end{array}$ & Sample size & $\mathrm{J}_{\mathrm{N}-4}$ & BIC1 & BIC2 & BIC3 & HQQ \\
\hline $\mathrm{I}_{1}$ & $29 / 07 / 2002-28 / 11 / 2008$ & 0.01 & $4(0.52)$ & $4(0.77)$ & $4(0.91)$ & $4(0.74)$ \\
$\mathrm{I}_{1}$ & $29 / 07 / 2002-30 / 04 / 2008$ & 0.01 & $1(0.52)$ & $4(0.64)$ & $4(0.85)$ & $4(0.525)$ \\
$\mathrm{I}_{1}$ & $29 / 07 / 2002-18 / 07 / 2007$ & 0.01 & $1(0.74)$ & $3(0.47)$ & $4(0.87)$ & $4(0.475)$ \\
\hline
\end{tabular}

Notes: The test formulas are defined in Ahn and Perez (2008). The number of randomizations of the cross-section ordering was set to 500 . $\mathrm{J}_{\mathrm{N}-4}$ shows number of rejections of the moment condition across randomizations when the true number of factors is 4 (test for independence of idiosyncratic errors and observable series). BIC1, BIC2, BIC3 and HQQ show the number of factors suggested by the criterion. The number in brackets is the empirical frequency of the selected number of factors over all randomization.

The set of correlates, $\mathrm{I}_{1}$ includes the high-yield spread, the VIX, the S\&P 500 Index, the spread on asset-backed commercial paper, the spread of the Libor over the overnight index swap, and the spread of the overnight index swap over the T-bill rate. 
Figure 1. Evolution of Spreads on Credit Default Swaps (median, basis points)

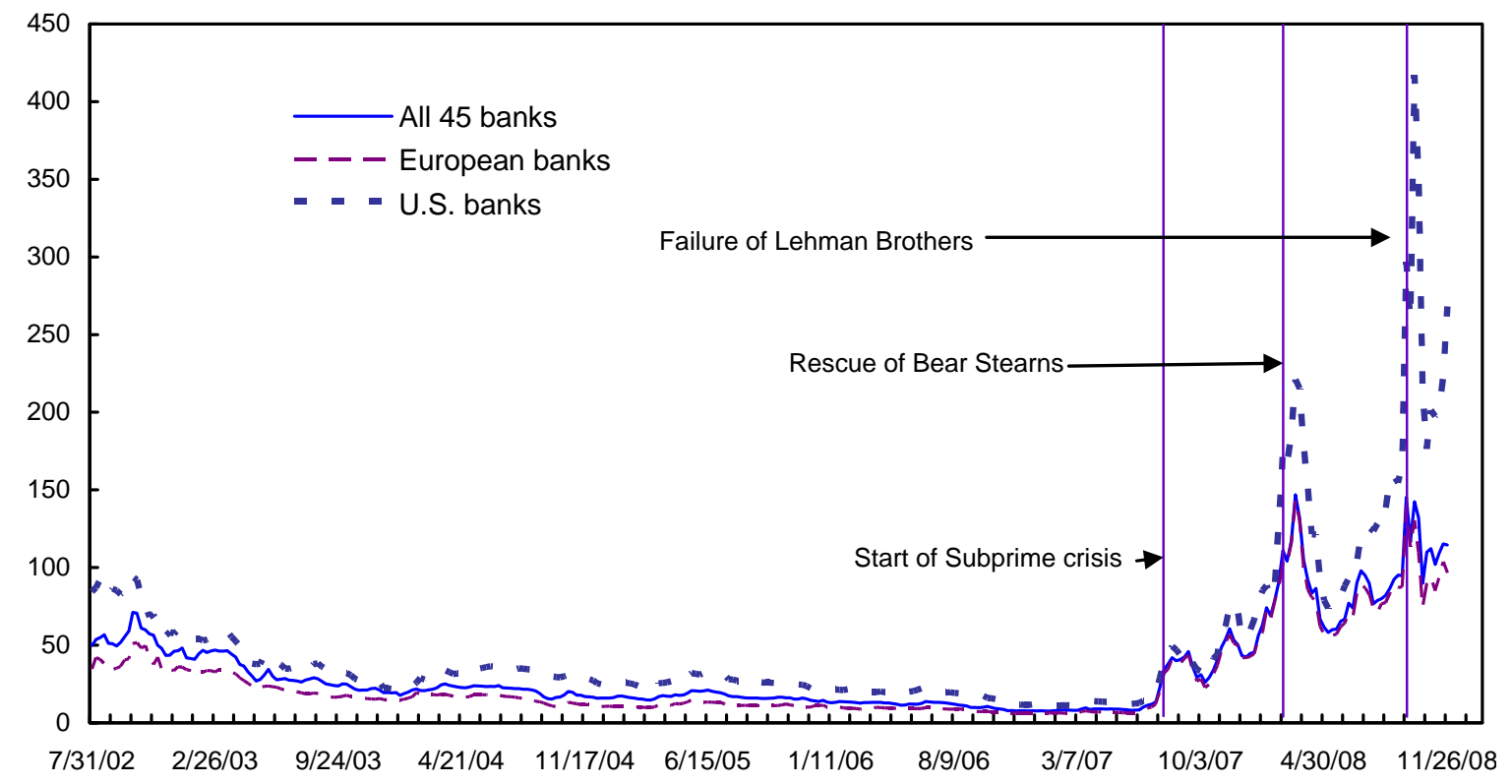

Figure 2. Share of CDS Spreads'Variation Explained by the Four Common Components

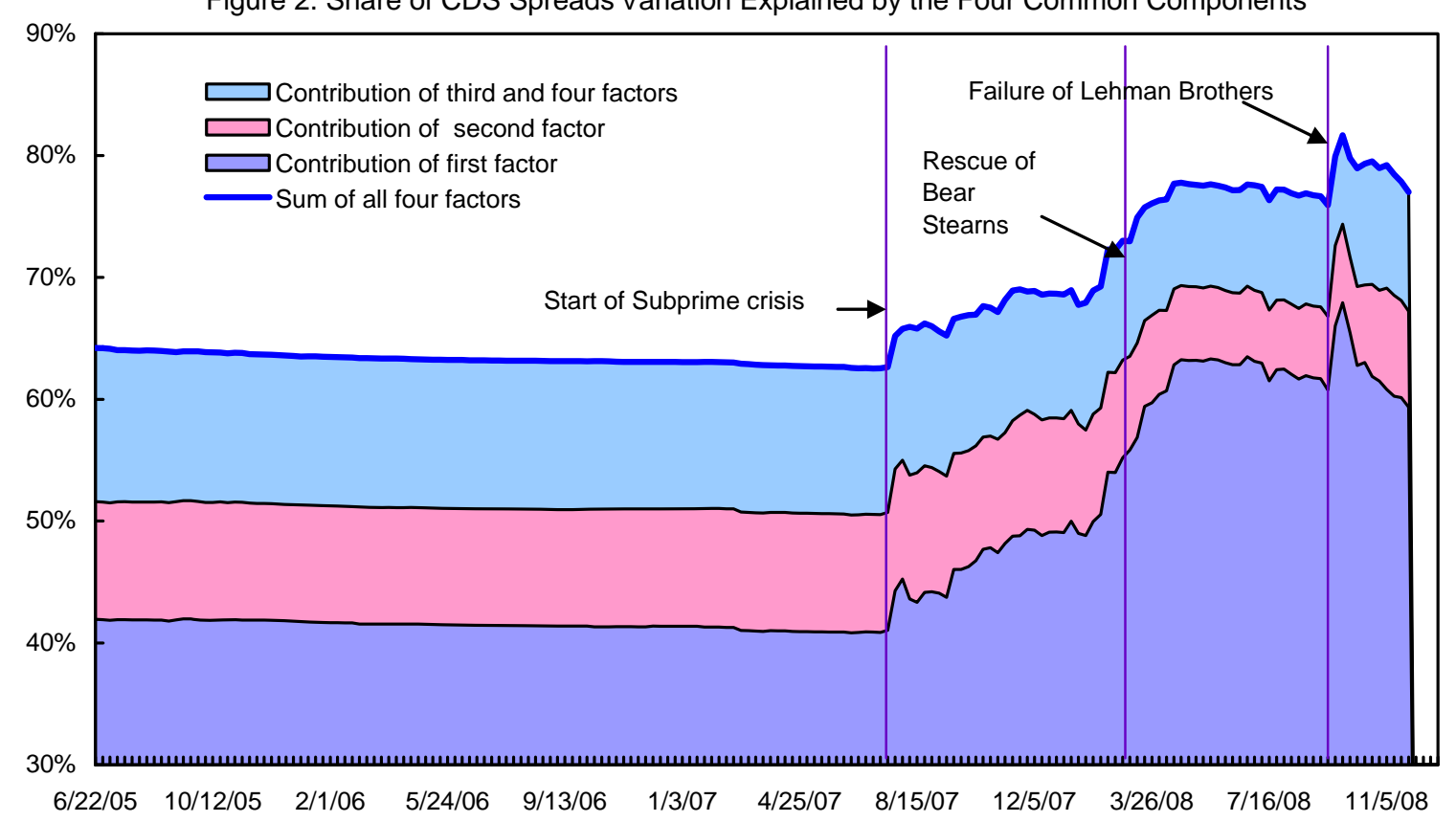


Figure 3. Additional Spillovers

(a) Fraction of Pairs of Banks Incurring "Additional" Spillovers
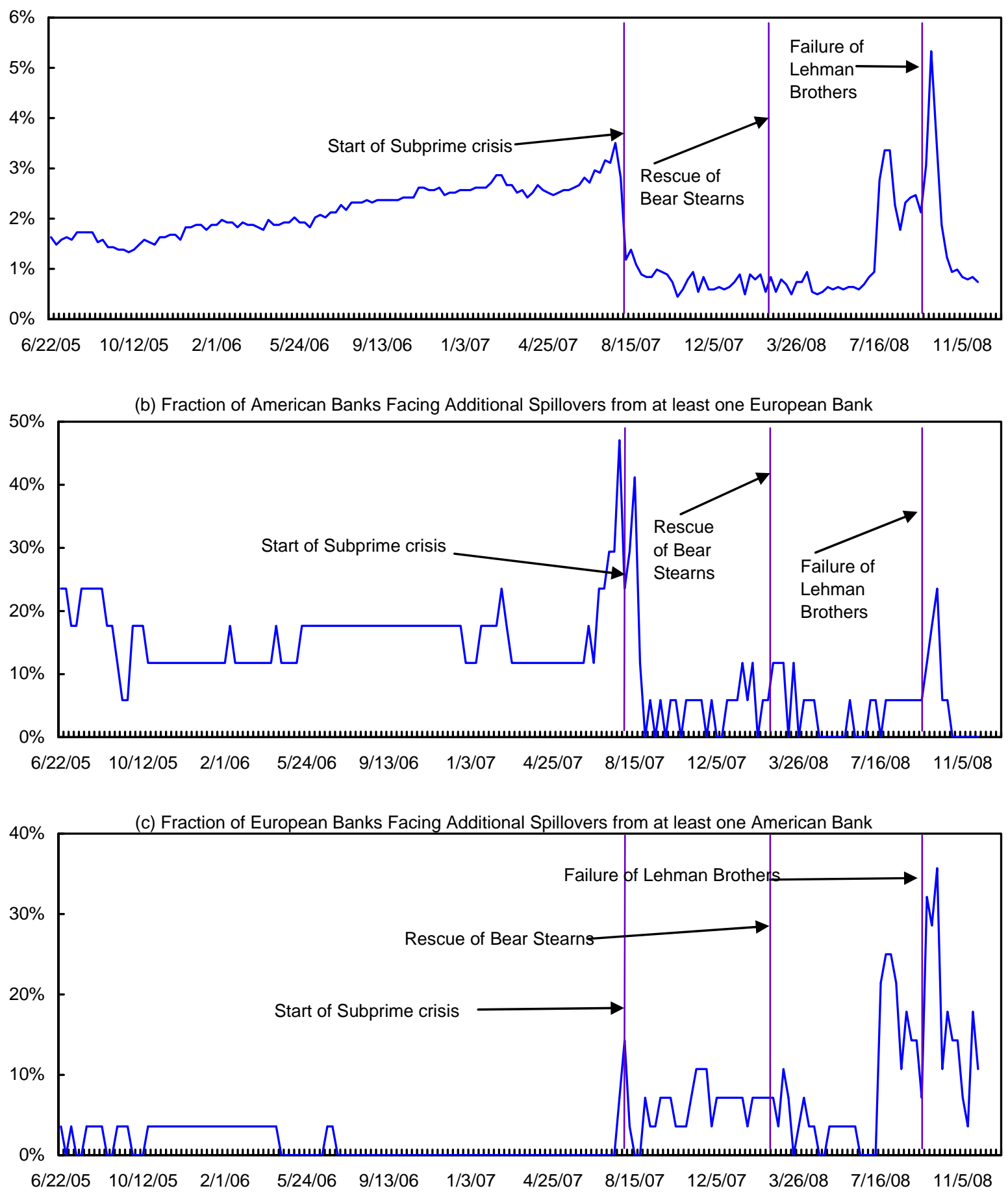
Figure 4. CDS spreads and the "Real Economy"

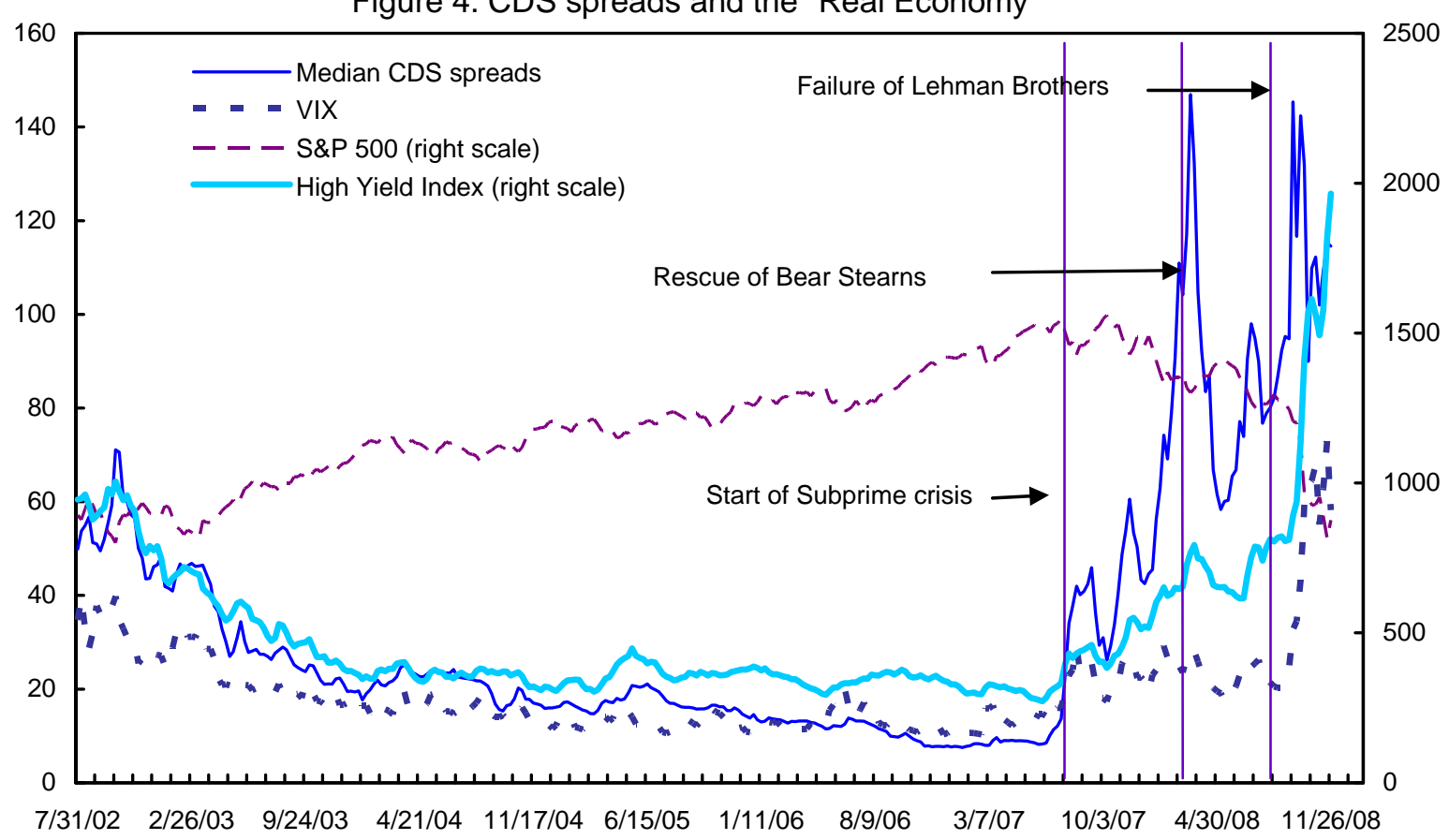


Figure 5. Correlation of Common Components with the "Real Economy"
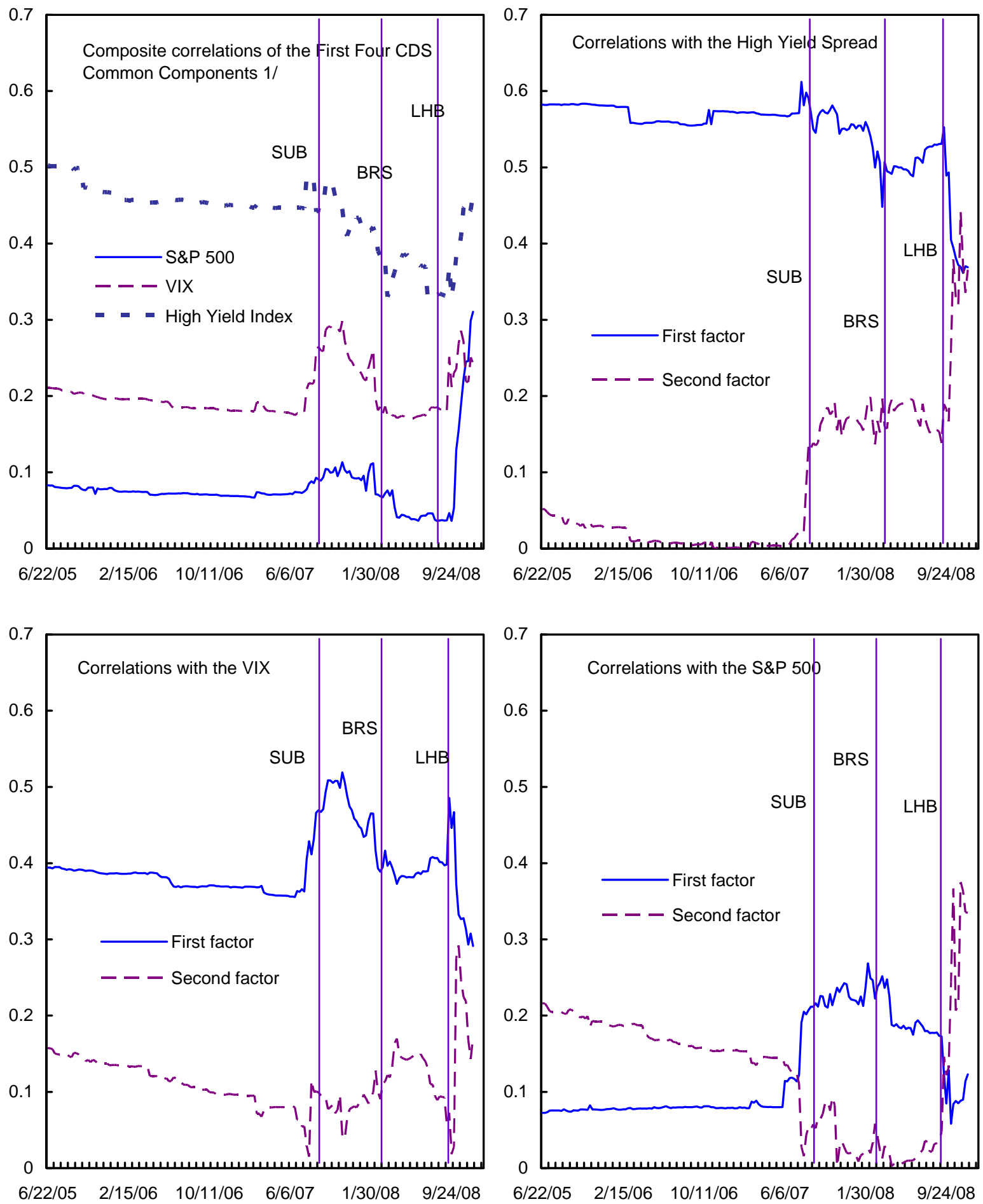

1/ Based on the R-squared criterion as discussed in the text.

Legend for vertical line indicators:

SUB = Start of Subprime crisis; BRS=Rescue of Bear Stearns; LHB=Failure of Lehman Brothers 
Figure 6. CDS spreads and Costs of Funding (basis points)

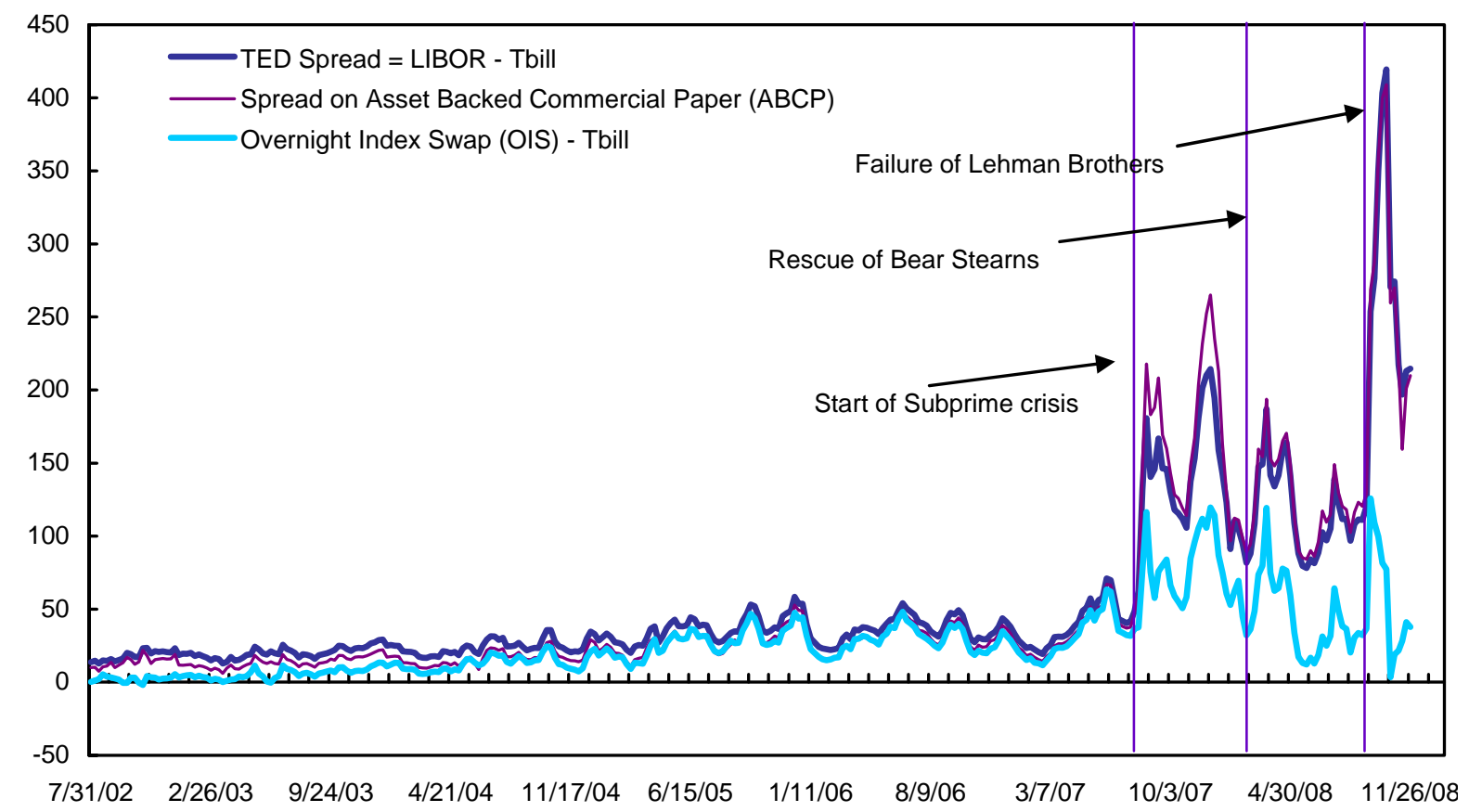


Figure 7. Correlation of Common Components with the Costs of Funding
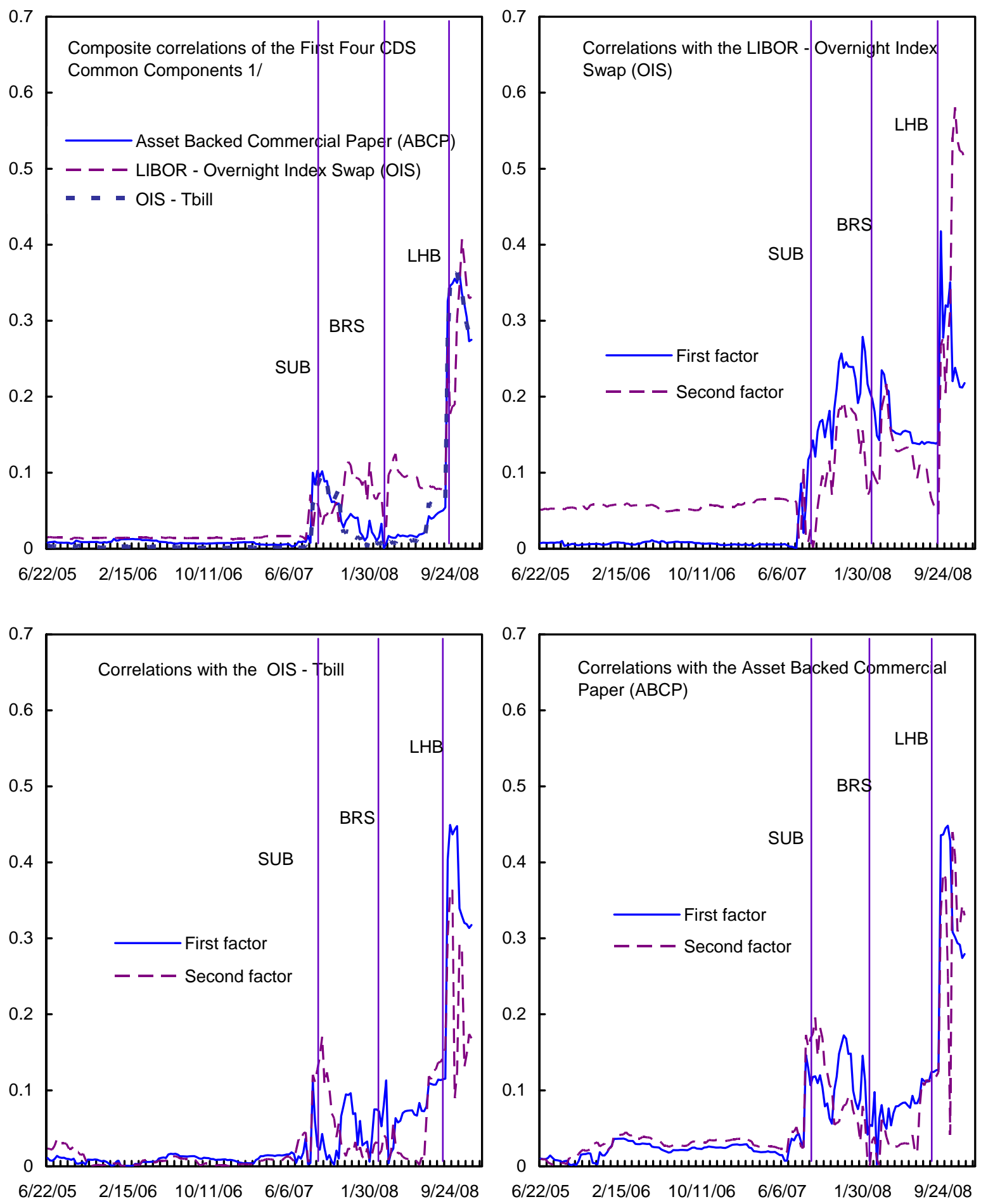

1/ Based on the R-squared criterion as discussed in the text.

Legend for vertical line indicators:

SUB = Start of Subprime crisis; BRS=Rescue of Bear Stearns; LHB=Failure of Lehman Brothers 


\section{References}

Ahn, Seung and M. Fabrizio Perez, 2008, "GMM Estimation of the Number of Latent Factors", Arizona State University mimeo.

Anderson, Helen and Farshid Vahid, 2007, "Forecasting the Volatility of Australian Stock Returns: Do Common Factors Help?" Journal of Business and Economic Statistics 25(1), pp.76-90.

Andrews, Donald W.K. and Biao Lu, 2001, "Consistent model and moment selection procedures for GMM estimation with application to dynamic panel data models", Journal of Econometrics 101, pp 123-164.

Bai, Jushan and Serena Ng, 2002, "Determining the Number of Factors in Approximate Factor Models", Econometrica 70(1), pp. 191-221.

Bai, Jushan and Serena Ng, 2006a, "Confidence Intervals for Diffusion Index Forecasts and Inference with Factor-Augmented Regressions”, Econometrica 74(4), pp. 1133-1150.

Bai, Jushan and Serena Ng, 2006b, "Evaluating Latent and Observed Factors in Macroeconomics and Finance", Journal of Econometrics 113, pp. 507-537.

Bai, Jushan and Serena Ng, 2008, "Extremum Estimation when the Predictors are Estimated from Large Panels", Annals of Economics and Finance, 9(2), pp. 201-222

Brunnermeier, M.K. 2009, "Deciphering the Liquidity and Credit Crunch 2007-08," Journal of Economic Perspectives, forthcoming.

Chamberlain, Garry and Michael Rothschild, 1983, "Arbitrage, Factor Structure and MeanVariance Analysis in Large Asset Markets", Econometrica 51, pp. 1281-1304.

Clark, Todd E. and Michael W. McCracken, 2005. "The power of tests of predictive ability in the presence of structural breaks", Journal of Econometrics 124(1), pp 1-31,

Davidson, Russell and James MacKinnon, 1985, "Heteroskedasticity-robust tests in regression directions", Annales de l'INSEE 59, pp. 183-218.

Eichengreen, Barry and Ashoka Mody. 2000. "What explains changing spreads on emerging market debt?" in Sebastian Edwards (ed.), Capital Flows and the Emerging Economies, Chicago: University of Chicago Press.

Goncalves, Silvia and Lutz Kilian, 2004, "Bootstrapping Autoregressions with Conditional Heteroscedasticity of Unknown Form," Journal of Econometrics 123, pp. 89-120.

Hansen, Bruce, 2000, "Testing for structural change in conditional models", Journal of Econometrics 97, pp. 93-115. 
Jones, Sam, 2009, "Why Letting Lehman Go Did Crush the Financial Markets," www.ft.com/alphaville (12 March).

Longstaff, F.A., Pan, J., Pedersen, L.H. and Singleton, K.J. 2008, “How Sovereign Is Sovereign Credit Risk?" UCLA and Stanford, mimeo.

Mody, Ashoka and Mark Taylor, 2003, "The High Yield Spread as a Predictor of Real Economic Activity: Evidence of a Financial Accelerator for the United States," IMF Staff Papers 50(3): 373-402.

Onatski, Alexei, 2006, "Determining the Number of Factors from Empirical Distribution of Eigenvalues," Columbia University mimeo.

Rossi, Barbara, 2005, “Optimal Tests for Nested Model Selection with Underlying Parameter Instability", Econometric Theory 21, pp. 962-990.

Soros, George, 2009, “The Game Changer,” Financial Times, January 28, http://www.ft.com/cms/s/0/49b1654a-ed60-11dd-bd600000779fd2ac.html?nclick_check=1

Stock, James and Mark Watson, 2002, "Forecasting Using Principal Components from a Large Number of Predictors," Journal of the American Statistical Association 97, pp. 1167-1179.

Taylor, John B., 2009, Getting Off Track: How Government Actions and Interventions Caused, Prolonged, and Worsened the Financial Crisis, Stanford, CA: Hoover Institution Press.

Zhang, Benjamin Yi-Bin, Zhou, Hao and Zhu, Haibin, 2008, "Explaining Credit Default Swap Spreads With the Equity Volatility and Jump Risks of Individual Firms,” FEDS Discussion Paper No. 2005-63; Review of Financial Studies, Forthcoming; BIS Working Paper No. 181. Available at SSRN: http://ssrn.com/abstract=713482 